Revista Cógnito v.2:1 (2020) 49 - 66

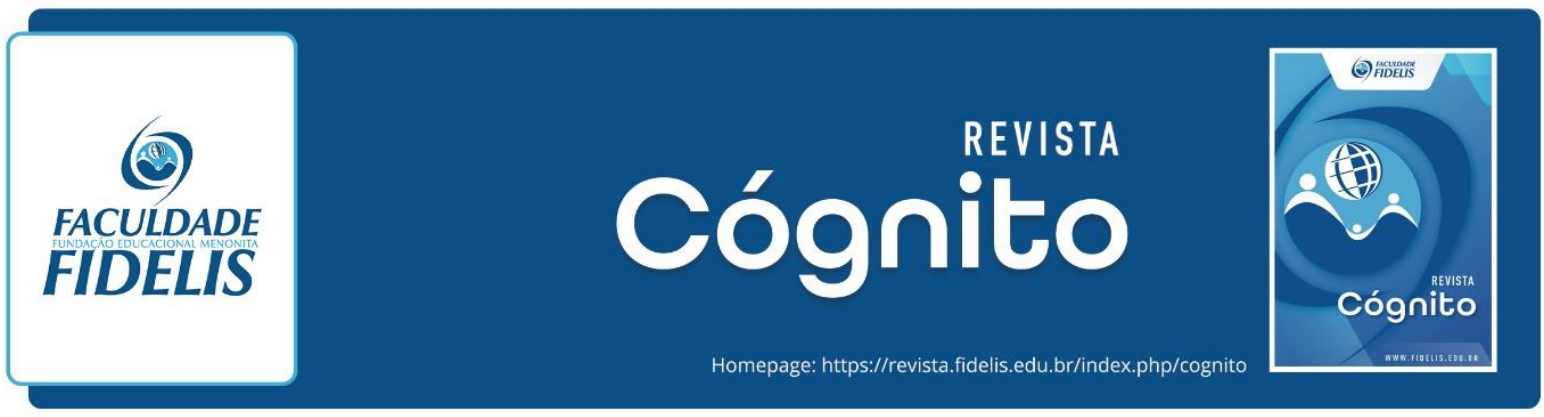

\title{
POR QUE MUITOS JOVENS NÃO PERMANECEM NA IGREJA E O QUE FAZER PARA MUDAR ESTA REALIDADE
}

\section{WHY MANY YOUNG PEOPLE DO NOT STAY IN CHURCH AND WHAT TO DO TO CHANGE THIS REALITY}

\author{
Altair Born ${ }^{1}$ \\ Ernst Werner Janzen²
}

\section{RESUMO}

Observa-se a grande quantia de adolescentes que participam das atividades da igreja evangélica com regularidade. Muitos são introduzidos à rotina de igreja desde o seu nascimento, passando por escola bíblica dominical, escola bíblica de férias, juniores e na sequência grupo de adolescentes e jovens. Muitos pais não medem esforços para levar seus filhos às programações, pois desejam sinceramente que os mesmos sigam o bom caminho. A grande questão é que muitos acabam se afastando da igreja e da fé após deixarem o grupo de adolescentes. Quais são as causas? Será que as programações têm sido relevantes em conduzir estes indivíduos para um compromisso real com Jesus? Por que muitos adolescentes não permanecem na igreja? Quem ou o que causa o êxodo? Através de pesquisa bibliográfica e pesquisa com "ex adolescentes" da $1^{\text {a }}$ Igreja Irmãos Menonitas do Boqueirão, esta pesquisa se propõe a descobrir algumas das possíveis causas do abandono e sugerir medidas que poderiam prevenir ou minimizar este fenômeno.

PALAVRAS-CHAVE: Igreja Evangélica. Jovens Evangélicos.

\begin{abstract}
Many teenagers are regularly attending evangelical church activities. Many of them are introduced to the church routine from birth on, through Sunday Bible school, vacation Bible school, juniors and the following group of teenagers and youth. Many parents don't measure efforts to take their children to the church activities because they sincerely want them to go the

\footnotetext{
${ }^{1}$ Especialista em Ministério Pastoral, Faculdade Fidelis. E-mail: altair.cruzverde@gmail.com

${ }^{2}$ Mestre em Teologia pela Faculdade EST. Docente da Faculdade Fidelis. E-mail: ernst.janzen@ fidelis.edu.br
} 
right way. The big issue is that many eventually drift away from the church and from faith after leaving the teen group. Have the programs been relevant in leading these individuals to a real commitment to Jesus? Why doesn't the teenager stay in church? Where is the gap? Who or what failed in the process? Through bibliographic research and research with "former teenagers" of the 1st Mennonite Brethren Church of Boqueirão. This research aims to discover some of the possible causes of abandonment and what measures could prevent and minimize this phenomenon.

KEYWORDS: Evangelical Church. Evangelical Teena

\section{INTRODUÇÃO}

Muitos jovens "criados" na igreja evangélica no Brasil decidem abandoná-la ainda na adolescência. Com base nesta problemática, este trabalho propõe-se a pesquisar algumas das possíveis causas desta realidade.

Este trabalho converge na pesquisa bibliográfica e estudo de campo. Este contactou jovens que já foram ligados de alguma forma a uma igreja evangélica da cidade de Curitiba/PR.

Realizada em 2015, o formulário de pesquisa foi enviado a setenta jovens, destes, obteve-se o retorno de vinte e quatro formulários, cerca de $30 \%$ do total. O formulário fazia perguntas relacionadas ao histórico de vida do jovem na igreja.

O foco da pesquisa: compreender as causas do êxodo; sugerir possíveis soluções; indicar ações preventivas e minimizadoras do êxodo de adolescentes.

O artigo é organizado segundo os seguintes conteúdos: análise do contexto; o abandono/êxodo; como ajudar os jovens num mundo em transformação; como os pais podem ajudar; e como os pastores e líderes podem ajudar.

\section{ANÁLISE DO CONTEXTO}

\subsection{PARTICIPAÇÃO NA IGREJA LOCAL}

O contexto local certamente apresenta peculiaridades e razões que contribuem para que o fenômeno do "êxodo". Entende-lo, é essencial a fim de chegar às melhores conclusões. 
Uma das perguntas da pesquisa de campo busca informações sobre a participação dos jovens na igreja. No gráfico 1 constata-se que a maioria, $41 \%$, foi incentivada e levada por algum familiar ou conhecido a participar de atividades na igreja desde a infância. Não há como identificar as motivações dos adultos ao fazerem isso. Pode-se considerar hipóteses: manter a tradição familiar, mostrar aos filhos o caminho da religiosidade, aprender coisas boas sobre Deus ou para ter bons amigos. O segundo aspecto mais alto aponta que, $18 \%$ dos jovens consideram que tiveram um encontro pessoal com Jesus e demonstraram isso através do batismo. $4 \%$ respondem que se batizaram por obrigação.

Gráfico 1: A participação na igreja.

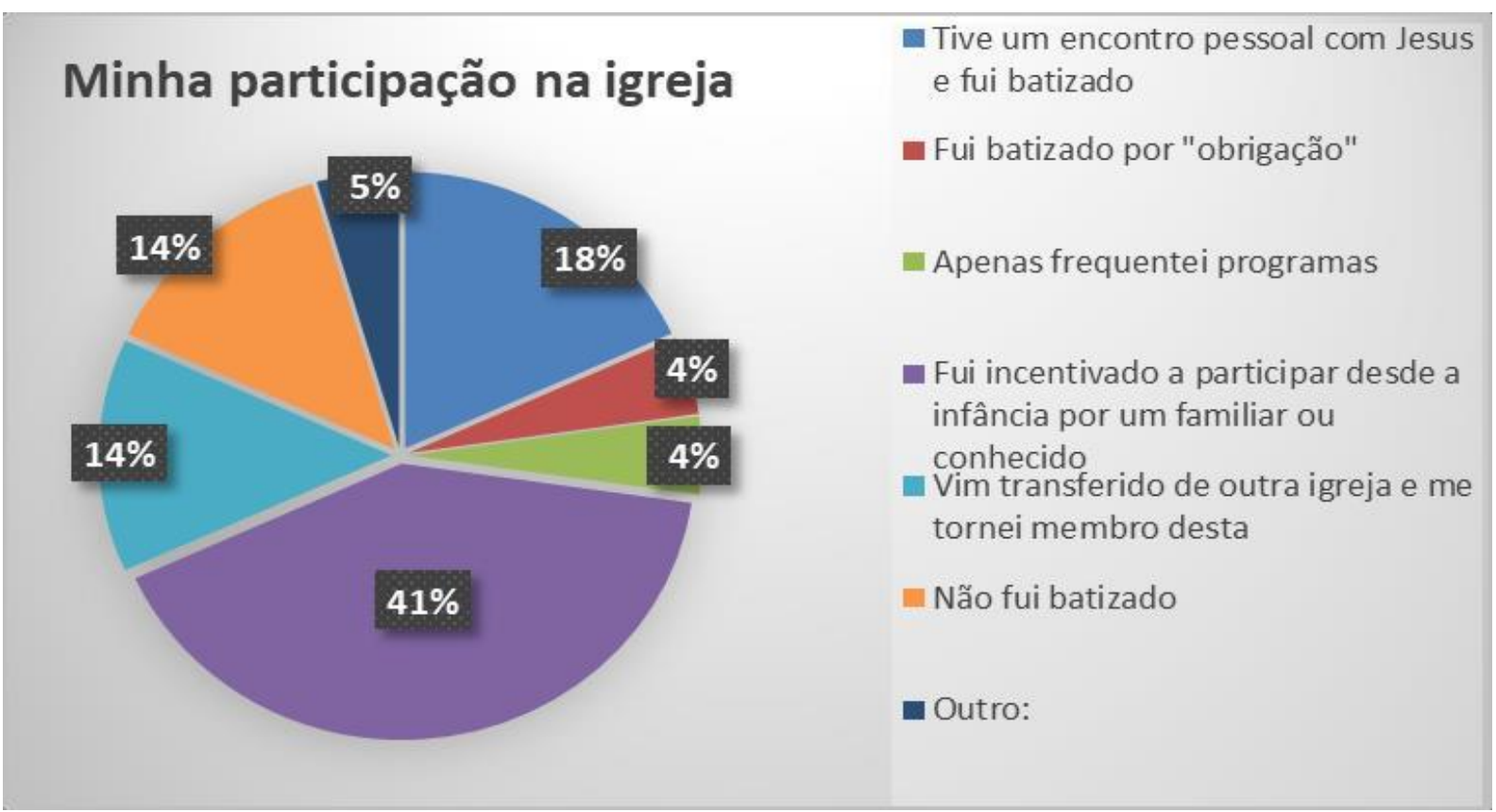

Fonte: Dados da pesquisa de campo.

Quanto ao significado de participação na igreja, 27\% afirmam que encontrar-se com os amigos era a motivação principal. 
Gráfico 2: O significado da participação na igreja.

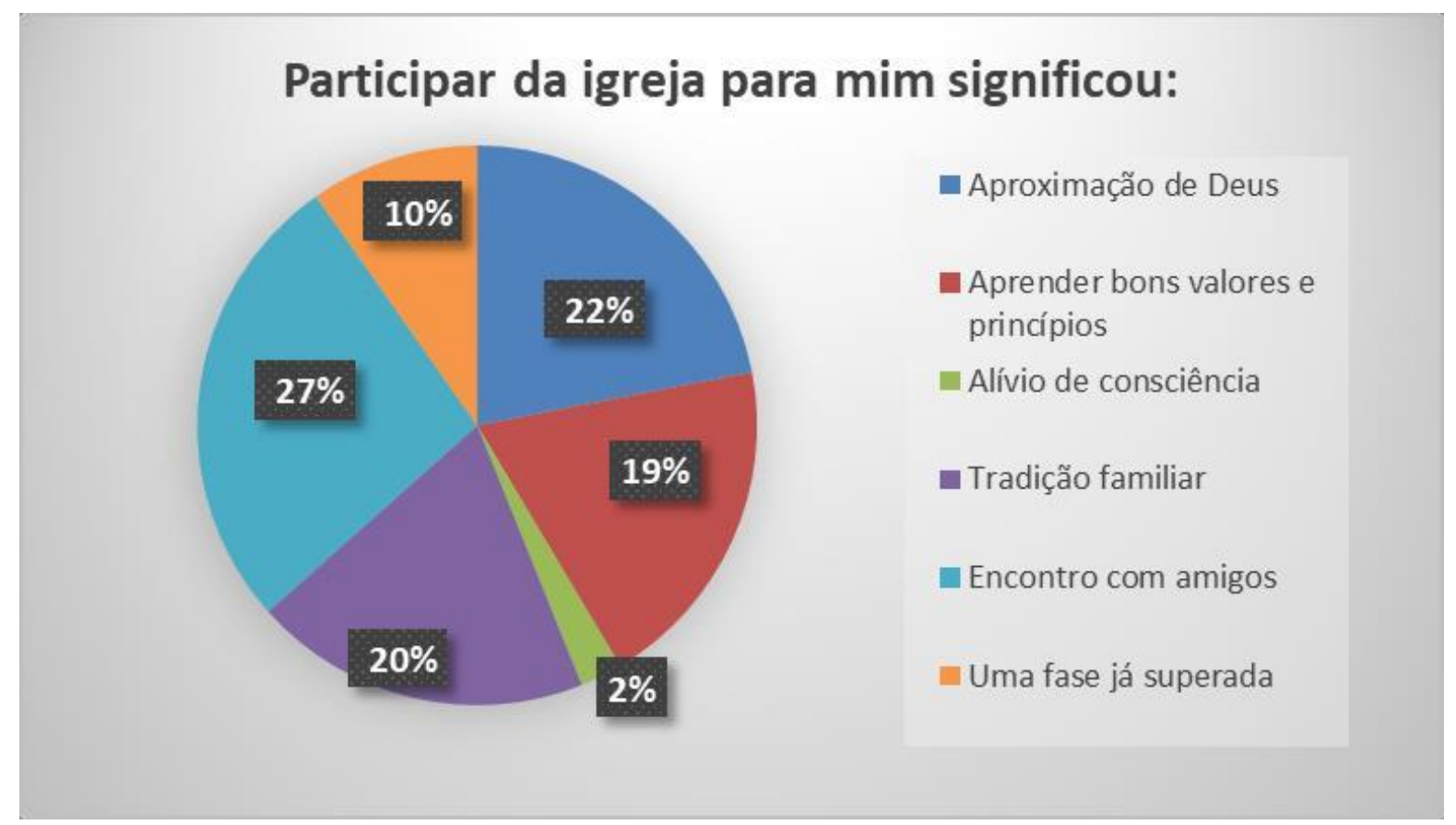

Fonte: Dados da Pesquisa de campo.

Para o jovem em formação em busca por sua identidade, a amizade é de grande valor. Collins (2004, p. 196) diz que há um grande desejo de serem aceitos e de se identificarem na linguagem, nos ídolos, na música, na maneira de se vestir e nas formas de diversão. Kemp (2005, p. 73) diz que não há outra época na vida em que a pessoa sinta tanta necessidade de ser aceito pela turma, quanto na adolescência.

O gráfico 2 mostra também que para 22\%, participar da igreja significou aproximação de Deus. Supõe-se que o ambiente amigável era também propício aos jovens para se aproximarem de Deus.

Segundo o gráfico 2, para 20\% a participação na igreja significou dar continuidade a uma tradição familiar. A tradição familiar pode contribuir muito a permanência na igreja, mas em alguns casos, pode ser um empecilho.

\subsection{PARTICIPAÇÃO NO GRUPO DE ADOLESCENTES}

No gráfico 3 há respostas quanto aos resultados da participação no grupo de adolescentes da igreja. A maioria, 23\%, declara que participava do grupo de adolescentes por causa dos amigos. Repete-se aqui, o que já foi constatado no gráfico 2 sobre o valor das amizades. Para $21 \%$, o grupo de adolescentes serviu para aprender bons princípios e valores e para $20 \%$, o 
ambiente era acolhedor. Constata-se que, com base nos gráficos 2 e 3, a participação na igreja teve aspectos muito positivos, pois ressalta as amizades, bons valores e o acolhimento.

Gráfico 3: Participação no grupo de adolescentes.

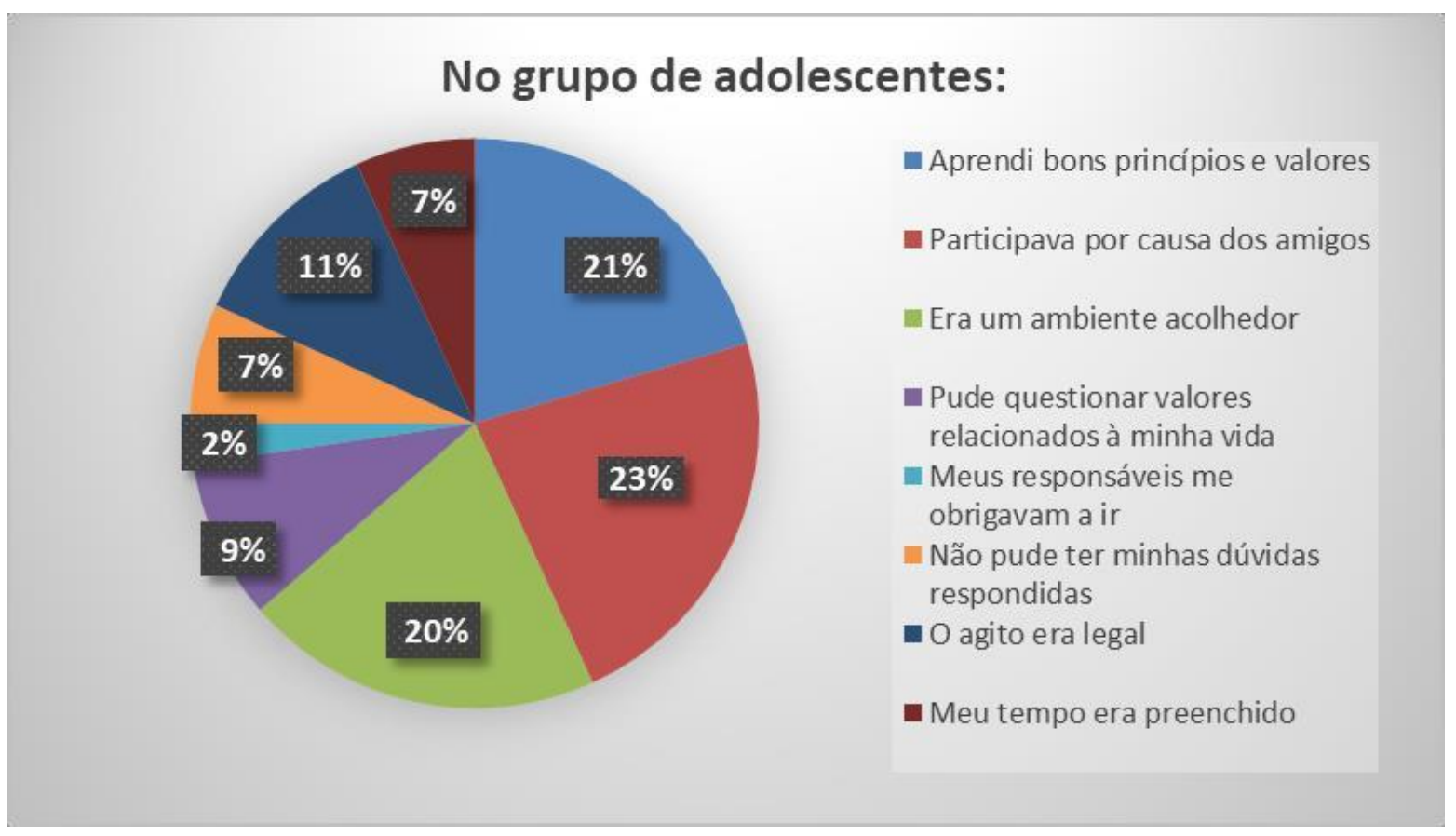

Fonte: Dados da pesquisa de campo.

Segundo Jaime Kemp (2005, p. 62), o adolescente só tem a ganhar quando percebe que é amado incondicionalmente e plenamente aceito, seja qual for seu desempenho. Kinnaman (2014, p. 120) faz uma interrogação pertinente: nossas igrejas e paróquias estão realmente proporcionando aos jovens o ambiente rico e diversificado de que uma geração voltada para o relacionamento precisa para desenvolver uma fé profunda?

A maioria dos adolescentes pesquisados considerou o ambiente acolhedor e com coisas boas a aprender. Mesmo assim, muitos deles abandonaram a igreja.

\section{O ABANDONO DA IGREJA}

\subsection{JOVENS QUE ABANDONAM A IGREJA}

A pesquisa procurou identificar algumas das possíveis razões que contribuíram para que muitos jovens abandonassem a igreja. O gráfico 4 apresenta algumas possíveis razões do abandono. $37 \%$ declarou que a decepção com pessoas foi a razão de saírem da igreja. 
Gráfico 4: Porque o jovem deixou de participar.

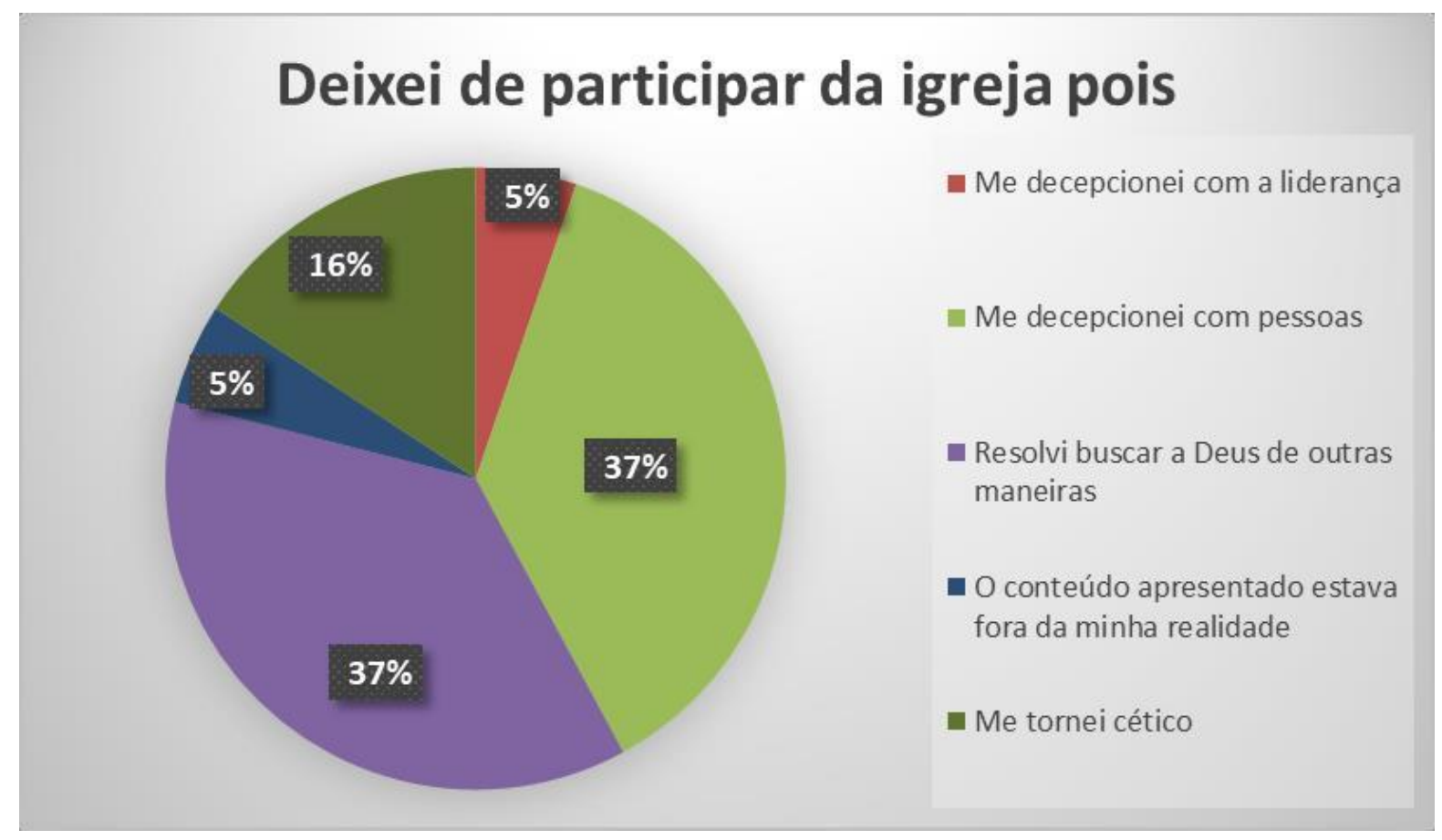

Fonte: Dados da pesquisa do autor.

O mesmo percentual, 37\%, resolveu buscar a Deus de outras maneiras. Sem identificar as outras formas de buscar a Deus, pode-se supor que a busca por outras igrejas ou movimentos podem estar relacionados à busca individual dos egressos.

O gráfico 4 também indica que $16 \%$ dos pesquisados se tornaram céticos, e por esta razão deixaram a igreja. Não há como identificar as razões do ceticismo, mas, estas podem estar ligadas à decepção com líderes e/ou amigos e até mesmo às dúvidas em relação a fé.

Palmer Becker afirma que,

os cristãos anabatistas defendem que o cristianismo inclui crenças, experiências espirituais e o perdão dos pecados. Mas, entre os cristãos dessa perspectiva se dá ênfase particular a seguir a Jesus na vida diária. Os cristãos anabatistas chegam ao ponto de dizer que cristianismo é discipulado (BECKER, 2019, p. 39).

Esta afirmação sugere que a vida com Deus se expressa no cotidiano e certamente não se limita apenas ao que acontece de forma regular nas estruturas físicas da igreja, o que claramente é insuficiente.

Ao autor desta pesquisa parece que a cultura e sua preservação são características fortes em igrejas como a IEIMB e muitas vezes parecem estar em uma categoria acima da própria fé 
em Cristo. Portanto, cabe avaliar qual é a parcela de contribuição da própria igreja no fenômeno de abandono de jovens.

Kinnaman sugere que,

a maioria das pessoas que abandonam a igreja, na verdade, não estão rejeitando a Deus ou a Cristo. Estão rejeitando uma instituição ou determinadas pessoas que alegam representá-los [...] os jovens estão em busca de respostas e de autenticidade [...] têm um faro apurado para a falsidade e a hipocrisia. E, quando eles sentem o cheiro delas, saem correndo (KINNAMAN, 2014, p. 225).

A institucionalização da igreja pode dificultar a experiência espiritual com Deus. A ênfase em regras, bem como no cumprimento de ritos e tradições podem distanciar os jovens.

\subsection{IGREJA QUE ABANDONA JOVENS}

É preciso também avaliar a eventual parcela de responsabilidade da própria igreja no processo de êxodo dos adolescentes.

O autor Kinnaman (2014, p. 10) cita a frase de um jovem católico que se afastou da igreja: "Não fomos nós que deixamos a igreja, mas, de certa forma, foi a igreja que nos deixou." Assim, na visão de muitos jovens, a igreja na verdade os abandona. O mesmo autor (2014, p. 11) afirma que toda uma geração de jovens acredita que as igrejas onde foram criados não são lugares seguros e hospitaleiros onde podem expressar suas dúvidas.

O autor acredita que:

Na maioria dos casos, estamos mandando ao mundo jovens despreparados para lidar com as mudanças sociais, tecnológicas e religiosas, [...] muitos são incapazes de raciocinar claramente sobre sua fé e relutam em correr riscos de verdade por amor a Cristo. (KINNAMAN, 2014, p. 28).

Lopes (2013, p. 12) afirma que falhamos muitas vezes em passar o bastão da verdade para a próxima geração. Em um estudo recente Lopes revela que a terceira geração de uma igreja já não tem mais o mesmo fervor da primeira.

Existem lacunas no modelo de ser igreja que acabam contribuindo para uma formação deficiente dos indivíduos jovens no sentido de prepará-los para o mundo e seus desafios. Podese afirmar que a igreja se ocupa em demasia com a manutenção de estruturas e tradições, negligenciando o cuidado e preparo das gerações futuras. 
Perguntados se voltariam para a igreja, 21\% dos jovens responderam que jamais voltariam (gráfico 5). Surpreendentemente, também $21 \%$ responderam que voltariam se as pessoas vivessem o que pregam. Seria interessante descobrir qual a percentagem dos resistentes que voltaria sob tal condição.

Gráfico 5: Possibilidades de voltar para a igreja.

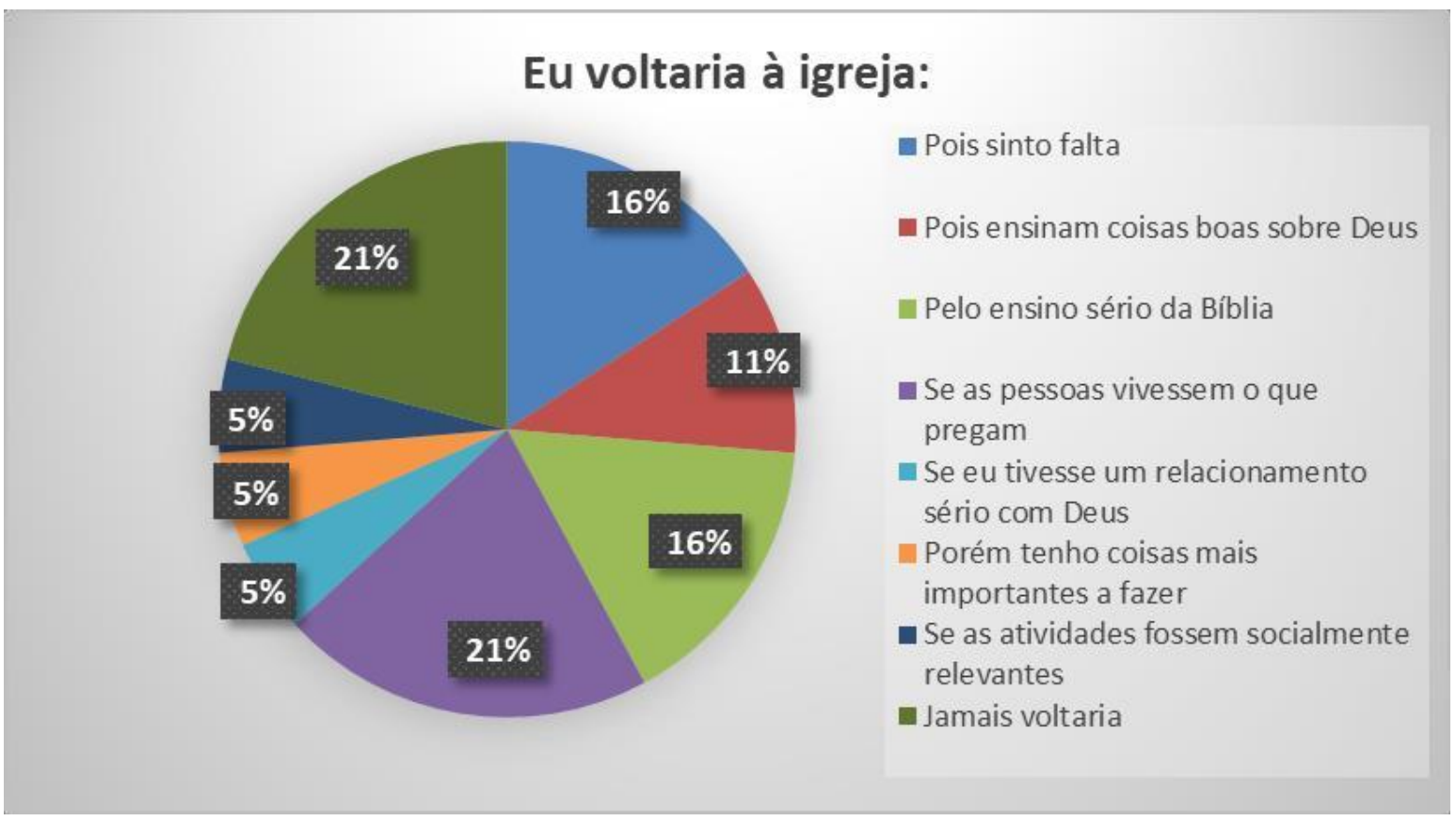

Fonte: Dados da pesquisa do autor.

De qualquer maneira, é possível que as decepções, já citadas anteriormente, estejam relacionadas à hipocrisia de membros, participantes de atividades e líderes da igreja, contribuindo para que jovens se afastem.

É necessário que, como afirma Reimer (2011, p. 266), nas igrejas as palavras e as ações sejam coerentes. A falta de consistência e a dissociação da vida de "domingo" com o resto da semana são um "tiro no pé” de qualquer instituição religiosa, sobretudo, das igrejas ou comunidades cristãs.

$\mathrm{O}$ autor Goheen cita que "certo cristão do segundo ou terceiro século observou: 'A beleza da vida faz com que pessoas de fora se juntem a nós [...]. Não falamos sobre grandes coisas; nós as vivemos"” (MINUCIUS FELIX, citado por GOHEEN et al., 2014, p. 24).

Ainda em resposta à questão do gráfico $5,16 \%$ voltariam à igreja, pois sentem falta da mesma e $16 \%$ voltariam pelo ensino sério da Bíblia. Estes resultados sinalizam que, apesar de decepções e ceticismo, existe a possibilidade de alguns retornarem. Cabe à igreja avaliar de que 
modo pode contribuir para que isso aconteça e principalmente, o que fazer para prevenir ou pelo menos minimizar o êxodo jovem da igreja.

\title{
2.3 PAIS QUE ABANDONAM OS FILHOS
}

As Sagradas Escrituras ensinam em Deuteronômio 6.8-9 que a Palavra de Deus deve ser ensinada aos filhos em todas as horas e momentos do dia. Ou seja, a fé começa em casa e nos locais mais inusitados do dia a dia.

Em muitos casos, os próprios pais são corresponsáveis pelo afastamento dos filhos da igreja, quando vivem uma fé aparente, uma religiosidade em franca dissociação de profissão de fé e ação cotidiana. Por melhores que sejam as intenções dos pais ao levarem os filhos à igreja, se não viverem a fé com autenticidade, transparência e humildade transmitirão mensagens ambíguas que afastarão os filhos pela hipocrisia.

Holmen afirma,

\begin{abstract}
Muitos dos problemas que as famílias enfrentam hoje são reflexos diretos do compromisso parcial que fizeram com o Senhor. Muitas famílias se 'disfarçam de cristãs' aos domingos, mas não querem 'ser cristãs' no resto da semana. E, depois, ficam se perguntando por que as coisas não andam bem. (HOLMEN, 2011, p. 23).
\end{abstract}

Thompson (2011, p. 62) questiona como os filhos acreditarão que a Bíblia tem a ver com tudo que acontece na vida, se é falado a seu respeito somente na hora da lição bíblica? A prática religiosa da fé ocupa-se em cumprir determinados rituais em certos locais e horários, entretanto, isso parece ser insuficiente na formação cristã de crianças e jovens.

Os dados da pesquisa indicam que as principais razões para o êxodo de jovens da igreja são: decepção com pessoas, ceticismo e a busca por Deus através de outras formas. A análise bibliográfica sugere que a própria igreja e os pais acabam contribuindo para o afastamento ao não prepararem bem os jovens para o mundo fora da "bolha". De que forma esta realidade poderia ser mudada? O que as famílias e a igreja poderiam fazer para mudar esse cenário? 


\section{COMO AJUDAR OS JOVENS NUM MUNDO EM TRANSFORMAÇÃO}

\subsection{ENSINANDO VALORES E PRINCÍPIOS}

O mundo está em constante mudança e com a evolução da tecnologia as transformações têm acontecido a passos largos. Lopes (2013, p. 8) afirma que a cada geração a igreja tem seus próprios desafios e necessidades. Kinnaman faz um questionamento pertinente sobre como podemos seguir Jesus e ajudar os jovens a seguir Jesus fielmente em uma cultura em drástica e constante transformação?

Quer estejamos inseridos em uma tradição católica, evangélica ou ortodoxa, precisamos ajudar a próxima geração de seguidores de Cristo a lidar bem com a adaptação cultural; precisamos ajudá-los a 'viver no mundo sem ser do mundo'. (KINNAMAN, 2014, p. 15).

Valores e princípios bíblicos e o modelo de vida de Jesus, são com certeza, aspectos vitais para enfrentar as mais diversas situações de vida. Kemp (2005, p. 35) afirma que a adolescência é a época em que as crianças substituem os pontos de interrogação por pontos de exclamação. Questiona-se tudo. Isso se refere a questões pessoais, familiares e também a aspectos relacionados à fé e à prática da vida de igreja.

Jacobsen (2009, p. 183) sugere que a igreja ensina as pessoas a se comprometerem com as cerimônias religiosas e programas. Mas, a necessidade urgente da igreja, segundo Joiner é:

Deixar de ser um povo que tão somente obedece a um conjunto de regras e se tornar uma nação que busca viver um relacionamento de amor com o Deus Criador. E não se esqueçam de que há uma nova geração ao seu redor, observando a postura de vocês diante de Deus (JOINER, 2012, p.58).

Lopes (2013, p. 55) concorda dizendo que a fé é muito mais que um conjunto de regras e doutrinas. É, sobretudo, relacionamento com Deus. As características de igreja "voltada para dentro" certamente explicam o porquê de tanto investimento em programações e entretenimento, procurando de certo modo "segurar" os jovens ou "protegê-los" das ameaças de fora da igreja. Segurar jovens com diversões do mundo é utopia. Há muito mais liberdade no mundo ao vivenciar as diversões. 
Algumas das críticas que os jovens cristãos ou ex-cristãos fazem à igreja: os cristãos demonizam tudo o que está fora da igreja; os cristãos têm medo da cultura pop [...] filmes e músicas; os cristãos fazem uma falsa separação entre o sagrado e o secular. Os cristãos não querem lidar com a complexidade e com a realidade do mundo (KINNAMAN, 2014, p. 98).

Por outro lado, há igrejas que se "aculturam" demais e desta forma acabam comprometendo a pureza do Evangelho. Se as raízes da fé não estiveram bem firmes certamente a formação de cada nova geração pode estar seriamente comprometida.

Stott (2011, p. 13) considera que não se deve preservar a santidade fugindo do mundo, nem a sacrificar se conformando a ele. Becker (2019, p. 20) afirma que Jesus é o centro da nossa fé. É o primeiro valor central da fé anabatista. Segundo o autor,

Não é suficiente saber algo a respeito de Jesus e da salvação [...] não é suficiente saber explicar o que tudo significa na História e como se encaixa. Sabedor disso, você precisa tomar uma decisão. Você seguirá Jesus? Dirá sim a ele? (BECKER, 2019, p. 22).

É necessário tomar a decisão de seguir Jesus no dia a dia, só assim, as verdades aprendidas sobre ele farão sentido. David Augsburger (apud BECKER, 2019, p. 22) diz que é sensato seguir Jesus Cristo de forma diária, radical e integral.

Pode-se concordar com a afirmação de Kinnaman (2014, p. 120) de que é necessário enxergar o papel lastimável que os cristãos, às vezes, desempenham, transmitindo uma fé superficial à próxima geração. O resultado pode ser, como descrito a seguir:

Em todo o país cresce o número de pessoas denominadas "sem igreja". Eles crescem de forma avassaladora como uma nova tribo informal, por todos os cantos, muitos deles tento saído ou desistido da igreja, seja ela de que expressão for, mas em especial aquelas reunidas em templos ou instituições eclesiásticas. (BOMILCAR, 2012 p. 16).

Estas citações reforçam a grande necessidade de a igreja preparar bem os jovens oportunizando o aprofundamento de suas raízes da fé em Cristo para, desta forma, encarar de forma segura as pressões que a vida diária exerce. Muito tem se investido em ambientes agradáveis com luzes, sons e bandas que mexem com as emoções. Sem que isso esteja errado, deve-se questionar se isso contribui para a transformação das pessoas, se há preparo e capacitação para enfrentar os questionamentos, dilemas e tentações que o mundo "fora da bolha" apresenta e se se aprende a andar com Jesus. 
Bonhoeffer (2016, p. 24) diz que Lutero teve de abandonar o mosteiro e retornar ao mundo, não porque o mundo em si fosse bom e santo, mas porque o mosteiro nada mais era que o mundo. Ou seja, não se consegue "proteger" ninguém das influências do pecado dentro de uma "bolha santa", a igreja e seus programas.

Urge que a igreja avalie seu modelo de discipulado, que questione os reais propósitos de programas e eventos. A manutenção de algumas práticas tradicionais é de fato relevante no processo de formação de discípulos de Jesus?

Becker afirma:

Os primeiros anabatistas viam a igreja como um grupo de cristãos peculiarmente aliançados que haviam sido reconciliados com Deus e uns com os outros. Eles procuravam a prestação de contas mútua em relação ao seu compromisso com Deus e com os outros, assumido no ato do batismo (BECKER, 2019, p. 150).

Seguir Jesus é uma prática diária que é fortalecida através de relacionamentos saudáveis com pessoas que nutrem o mesmo desejo e propósito.

\subsection{PRATICANDO O ACOLHIMENTO E ACEITAÇÃO}

A sociedade de modo geral é competitiva. Pessoas são comparadas e levadas a viver em disputas por poder e posição. Quem não produz é rotulado e descartado. No ambiente escolar os alunos "nota 10" são exaltados e aplaudidos gerando, muitas vezes, insegurança e baixa autoestima naqueles considerados "medianos", como se a nota 10 fosse a principal evidência de competência dos indivíduos. A igreja tem a grande oportunidade de ser referência de acolhimento.

Segundo Bomilcar (2012, p. 9), a experiência comunitária cada vez menos é a marca da maioria das igrejas. Ramos (2009, p. 21) afirma que a igreja precisa assumir-se como uma comunidade terapêutica, em que as pessoas possam ser transparentes e amadas como são.

No Corpo de Cristo (igreja) todos têm importância e são preciosos. Como no corpo todos os membros são importantes, na igreja todos são importantes, por mais diversos que as pessoas sejam entre si (1 Coríntios 12.12-26). Desse modo todos podem se sentir acolhidos e úteis para servir com seus dons e talentos. 


\subsection{PREPARAR OS JOVENS ATRAVÉS DO DISCIPULADO}

Se a igreja não desenvolver intencionalmente uma vida de discipulado, o êxodo de jovens poderá continuar. É necessário preparar o indivíduo desde a mais tenra idade a tornar-se um discípulo de Jesus. Se isto não acontecer, não há programação interna que o segure e o êxodo certamente continuará. Ao sair "da bolha" os jovens se deparam com um mundo que é divertido, repleto de prazeres e que questionará muito a sua fé. Alguém sugere que discipulado pode ser entendido como "descer para o lado", ou seja, descer do nível de conforto próprio e andar junto com alguém ajudando-o a dar passos ao lado de Jesus.

O autor Becker (2019, p. 39), sugere que discipulado significa seguir Jesus na vida diária. Isso exige viver o mesmo modo de vida que Jesus viveu. O mesmo autor (ibid, p. 43) afirma que o discipulado é o resultado da transformação que vem por meio do relacionamento com Jesus Cristo. É uma maneira empolgante de ver e viver a fé cristã. Isso se aprende através de relacionamentos comprometidos com Jesus e uns com os outros.

A igreja deveria aproveitar os professores de biologia, de física, história, filosofia e outros para instruir e orientar os jovens ajudando-os a pensar biblicamente em paralelo às análises e estudos científicos.

Os jovens universitários são confrontados constantemente com questionamentos acerca de fé em Deus. A igreja pode tornar-se mais relevante se ousar encarar os questionamentos dos jovens. Isso se faz indo ao encontro de suas dúvidas e oportunizando um ambiente que os ajude a pensar. As suas dúvidas precisam ser acolhidas, respeitadas e discutidas e o ambiente em pequenos grupos favorece isso de modo peculiar.

O pensamento tradicional, segundo Kinnaman (2014, p. 203), é que "[...] a igreja existe para preparar a próxima geração para cumprir a vontade de Deus.” Esta mentalidade precisa mudar para "[...] a igreja é uma parceira de gerações que cumprem a vontade de Deus em sua época."

Crianças e adolescentes precisam que os adultos sejam exemplos de caráter e temor a Deus hoje. Precisam que os mais velhos tenham humildade para ouvir o que os mais novos têm a dizer. Que os ajudem a discernir a voz de Deus. Muito do que a igreja "fala" e faz hoje, a geração mais jovem não entende.

O escritor Francis Chan (apud KINNAMAN, 2014, p. 216) diz que o tempo de simplesmente trazer nossos amigos a um evento para que o pastor possa salvá-los e discipulá- 
los precisa acabar. De fato, todos os crentes precisam fazer o trabalho de evangelismo e discipulado. Thompson (2011, p. 62) afirma que o discipulado é mais eficaz quando a prática é integrada ao ritmo da vida diária.

\subsection{OPORTUNIZANDO BOAS AMIZADES}

Segundo Bernardo (2010, p. 16), o perigo, principalmente para os adolescentes que cresceram na igreja, é que a fé cristã seja identificada com a infância, com o que é familiar, e igualmente também seja deixada para trás.

Boas amizades são vitais para esta geração que necessita fazer parte de uma "tribo". A adolescência é a fase de descobertas e busca por identidade. É preciso ajustar-se às transformações físicas, interagir com a influência de grandes pressões sociais e terceiro, tomar decisões importantes sobre valores, identidade, profissão, relacionamentos, inclusive com o sexo oposto (COLLINS, 1980, p. 191).

O papel da igreja em promover amizades saudáveis é essencial na fase do indivíduo jovem que vive sob intensa pressão, inclusive em casa. Collins (2004, p. 209) afirma que a maioria das igrejas sabe o quanto é importante o apoio e o encorajamento das amizades na adolescência.

\section{COMO OS PAIS PODEM AJUDAR}

\subsection{SENDO EXEMPLO}

O escritor Mark Holmen sugere:

Se quisermos que nossas crianças tenham uma fé que influencie o caminho que tomam na vida e as decisões críticas que farão no futuro, então, precisamos ser modelos de fé em nossa família por intermédio de um relacionamento pessoal com Jesus Cristo. (HOLMEN, 2011, p. 49).

De modo similar, Brunes, Stroope (2011, p. 17), que afirmam que o lar é o contexto primário de nossa formação espiritual para melhor ou pior, diz também que (2011, p. 22) não importa o quão criativamente proclamemos a Palavra de Deus para nossos filhos na igreja, pois eles estarão mais inclinados a acreditar em suas experiências de fé em casa. O exemplo sem dúvida fala mais alto do que palavras (KEMP, 2005, p. 57). É imprescindível aos filhos observarem um modelo positivo de pais.

O escritor menonita Drescher (1998, p. 17) afirma que não existe lugar que exerça uma influência maior do que o ambiente familiar. Os pais influenciam os filhos, quer queiram, quer 
não. Definitivamente os pais precisam decidir qual caminho seguir, pois se desejam que os filhos encontrem o "bom caminho", eles precisam certificar-se de andar por este caminho. Não de forma religiosa e ritualística, mas de forma relacional e de dependência diária do Senhor.

Os autores Jacobsen, Coleman (2009, p. 125), afirmam que as crianças aprenderão a verdade à medida que a família as ajudar a vivê-la. Simples ritos religiosos que se limitam a horários específicos na igreja são insuficientes. Para que os filhos aprendam sobre a fé em Deus, necessitam ver isso no dia a dia de maneira relacional e integral.

\subsection{DEDICANDO TEMPO}

Alguém sugeriu certa vez que as crianças traduzem a palavra amor como "TEMPO". Elas necessitam que os pais dediquem tempo aos filhos através do comer juntos, viajar juntos e assim conduzi-los a Jesus.

Kemp (2005 p. 59), diz que, investir tempo na família é absolutamente fundamental para que os filhos desenvolvam sentimentos de unidade familiar, amor e cuidado recíproco. Fazer coisas juntos e conhecer lugares são oportunidades ótimas para conversar sobre Deus, sua criação e vontade. Isso vai além de ler algum livro devocional juntos e de participar de programas regulares da igreja.

George Barna (apud HOLMEN, 2011, p.77),

em sua pesquisa para o livro Transformando Crianças em Campeões, descobriu que em uma semana típica, menos de $10 \%$ dos pais que frequentam regularmente a igreja com os filhos, leem a Bíblia junto com eles, oram com eles (além da oração antes das refeições) ou participam de um ato devocional como uma unidade familiar. Um número ainda menor de famílias, uma em cada 20, têm, em um mês típico, algum tipo de experiência com Deus junto com os filhos fora da igreja.

Uma pequena quantidade de intencionalidade e prática pode mudar tudo isso.

\section{COMO OS PASTORES E LÍDERES PODEM AJUDAR}

\subsection{PODEM SER EXEMPLO, POIS ESTE FALA MAIS ALTO}

A vida prática de fé é essencial para influenciar e inspirar as gerações mais novas. Isso se aplica também aos pastores e líderes das igrejas. Diz Collins (1980, p.2012): 
Como é natural, rebelião, abuso de drogas e imoralidade ocorrem na igreja e em grupos ligados a ela, mas quando líderes sensíveis e interessados estão disponíveis para dar orientação e ensino espiritual, ajudar os participantes a se divertirem, inspirar autoestima, prover um lugar onde discutir problemas reais, e dar apoio emocional e social, a igreja tem então condições de fazer um tremendo impacto positivo e preventivo sobre os jovens. O exemplo é um dos modelos mais eficazes de ensinar adolescentes.

Jovens buscam referenciais em quem possam se inspirar e espelhar. Líderes que sejam transparentes, com caráter transformado através de um andar diário com Cristo, reconhecendo as limitações e fraquezas e declarando sua dependência de Deus, impactam e inspiram.

\subsection{OPORTUNIZANDO A INTERAÇÃO ENTRE AS GERAÇÕES}

Um dos grandes desafios da igreja local está em como manter a unidade em meio à diversidade de idades. Os mais velhos normalmente não entendem as novidades que os mais novos desejam implementar e os mais novos não apreciam os formatos e muitas tradições dos mais velhos.

Segundo Kinnaman (2014, p. 227), as pesquisas feitas para o livro "Sticky Faith" mostram que, quanto mais os jovens se envolvem na vida da igreja em geral, mais forte será a sua fé. A constatação é que na maioria das igrejas as atividades de adolescentes e jovens é segregada do restante da igreja e faz-se necessário aproximar as gerações para que convivam e aprendam umas com as outras.

\subsection{SERVINDO JUNTOS}

A unidade e a união transformam: realizar mutirões para servir a comunidade em que adolescentes e adultos trabalhem lado a lado, pintar as paredes de uma escola pública. Organizar pequenos grupos de encontros de adolescentes, jovens e adultos para compartilhar experiências e ouvir-se mutuamente pode demonstrar o modelo de vida em Cristo. Servir juntos para o bem maior aproxima as gerações, e desta forma os mais velhos serão bons exemplos aos mais novos.

Joiner (2012, p. 41) afirma que, se quisermos mobilizar a próxima geração, a fim de que ela se torne igreja, então os líderes precisam ser a Igreja. Se queremos que os jovens permaneçam na igreja, eles precisam aprender com os mais velhos a ter um relacionamento pessoal com Jesus. 


\section{CONCLUSÃO}

O impacto de líderes da igreja ou dos próprios pais, ao não viverem o que pregam e falam, é danoso, pois as crianças e adolescentes estão "de olho" observando o que acontece.

Esta pesquisa indica que a hipocrisia e a decepção com pessoas da igreja são algumas das principais razões de jovens abandonarem a igreja. Além destas, pode-se supor que há outras variáveis, tais como a influência forte de amigos não cristãos, o namoro com alguém que não tem a mesma fé e dúvidas relacionadas a Deus e a espiritualidade.

Há jovens que abandonam a igreja por razões diversas e muitas vezes como resultado de escolhas incoerentes com a fé cristã. Há igrejas que abandonam os jovens. Isso acontece ao serem muito focadas em suas formas históricas, tradicionais e principalmente por descuidarem de uma melhor preparação dos indivíduos jovens para "o mundo".

Adolescentes enfrentam uma fase de descobertas e transformação em seu corpo e mente e as boas amizades são essenciais neste processo. A igreja cristã tem a grande oportunidade de proporcionar um ambiente acolhedor e de aceitação destes indivíduos "em crise" e auxiliá-los no desenvolvimento de sua identidade pessoal e principalmente com Cristo.

Entende-se que a fé começa em casa e a parceria de pais e igreja certamente pode gerar impacto positivo preparando esta geração para "sair da bolha" de forma mais estruturada. Os pais têm importância fundamental pois são a influência primária na formação cristã dos filhos.

Conclui-se com este estudo que é possível mudar a realidade do êxodo da igreja, com um melhor preparo dos jovens através de discipulado e com referenciais exemplares que os ajudem diante dos dilemas da vida.

\section{REFERÊNCIAS}

BECKER, Palmer. Princípios anabatistas essenciais. Curitiba: Esperança, 2019.

BERNARDO, José. Líder adolescente. Santo André: Salva Vidas, 2010.

BÍBLIA SAGRADA. Nova Versão Internacional. São Paulo: Vida, 2015.

BOMILCAR, Nelson. Os sem igreja. São Paulo: Mundo Cristão, 2012.

BONHOEFFER, Dietrich. Discipulado. São Paulo: Mundo Cristão, 2016. 
BRUNES, Kurt. STROOPE, Steve. A fé começa em casa. Rio de Janeiro: Thomas Nelson Brasil, 2011.

COLLINS, Gary R. Aconselhamento cristão. Edição século 21. São Paulo: Mundo Cristão, 2004.

DRESCHER, John. M. Passando aos filhos a tocha da fé. São Paulo: Mundo Cristão, 1998.

GIBBS, Eddie. Para onde vai a igreja. Curitiba: Esperança, 2012.

GOHEEN, Michael. W. A igreja missional na Bíblia. São Paulo: Vida Nova, 2014.

HOLMEN, Mark. A fé começa em casa. Pompéia: Universidade da família, 2011.

JACOBSEN, Wayne; COLEMAN, Dave. Por que você não quer mais ir à igreja? Rio de Janeiro: Sextante, 2009.

JOINER, Reggie. Pense laranja. Pompéia: Universidade da família, 2012.

KEMP, Jaime. Meu filho cresceu e agora? São Paulo: Hagnos, 2005.

KINNAMAN, David. Descrentes. Pompéia: Universidade da família, 2012.

KINNAMAN, David. Geração perdida. Pompeia: Universidade da Família, 2014.

LOPES, Hernandes Dias. Para onde caminha a igreja. São Paulo: Hagnos, 2013.

RAMOS, Ariovaldo. Ação da Igreja na cidade. São Paulo: Hagnos, 2009.

REIMER, Johannes. Abraçando o mundo. Curitiba: Esperança, 2011.

STOTT, John. O discípulo radical. Viçosa: Ultimato, 2011.

THOMPSON, Tad. Pais discipuladores. São Paulo: Vida Nova, 2011. 